\title{
IDENTIDAD PROFESIONAL Y SOCIALIZACIÓN DE GÉNERO: UN ESTUDIO DESDE LA MANUALÍSTICA ESCOLAR EN LA ESPAÑA DEMOCRÁTICA ${ }^{\alpha}$
}

\author{
Professional identity and gender socialization: a study from \\ school textbooks in democratic Spain
}

\section{Virginia Guichot-Reina ${ }^{\beta}$ y Ana María De la Torre-Sierra ${ }^{\gamma}$}

Fecha de recepción: 19/09/2019 • Fecha de aceptación: 15/02/2020

Resumen. La construcción de la identidad profesional es un tema de interés para diferentes disciplinas como la antropología, la psicología o la educación. Siguiendo el enfoque del constructivismo social, ${ }^{1}$ entendemos que esta tiene un carácter narrativo y dinámico y que se forma a partir de la interiorización de discursos sociohistóricos vigentes en las situaciones con las que el sujeto interacciona. Durante la década de los años setenta del siglo XX, el mercado laboral en España experimentó una masiva incorporación de las mujeres, promovida por progresos sociales y legislativos en educación y empleo. Tales avances, unidos a los cambios provocados por la llegada de la democracia, han supuesto y suponen una importante renovación de la identidad femenina en el ámbito económico. El manual escolar, principal recurso didáctico utilizado en la educación

\footnotetext{
${ }^{\alpha}$ Este trabajo se inserta dentro del proyecto de investigación «Economía, patriotismo y ciudadanía: La dimensión económica de la socialización política en los manuales escolares españoles desde el Tardofranquismo hasta la Transición»(Ministerio de Economía y Competitividad, EDU201678143-R).

B Dpto. de Teoría e Historia de la Educación y Pedagogía Social, Facultad de Ciencias de la Educación, Universidad de Sevilla. C/ Pirotecnia 19, 41013 Sevilla, España. guichot@us.es (D) https://orcid. org/0000-0001-8802-7627

$\checkmark$ Dpto. de Teoría e Historia de la Educación y Pedagogía Social, Facultad de Ciencias de la Educación, Universidad de Sevilla. C/ Pirotecnia 19, 41013 Sevilla, España. adelatorre@us.es (DD https://orcid.org/0000-0001-7064-6761

1 Vivien Burr, An introduction to social constructionism (London: Routledge, 1995); Audrey Collin y Richard A. Young, «The future of career», en The future of career, eds. Audrey Collin y Richard A. Young (Cambridge: Cambridge University Press, 2002), 276-300.
}

Cómo citar este artículo: Guichot-Reina, Virginia y Ana María De la Torre-Sierra. «Identidad profesional y socialización de género: un estudio desde la manualística escolar en la España democrática». Historia y Memoria de la Educación 12 (2020): 101-136 
formal, se presenta como un instrumento socializador con poder relevante en la transmisión y configuración de una cultura sociolaboral, que será sesgada en caso de contener estereotipos de género. Nuestra investigación examina un total de veinte libros de texto de Educación Primaria de las áreas de Lengua y Sociales en dos periodos de la España democrática - Transición política y actualidad-, estudiando la identidad profesional femenina vinculada a la socialización económica difundida mediante este material. Los resultados desvelan una escasa participación de las mujeres como sujetos económicos en los manuales, mostrando una insuficiente representación femenina en el desempeño de actividades remuneradas, así como una falta de diversidad profesional que pone en relieve una gran desigualdad en los procesos de socialización entre hombres y mujeres contrarios a valores coeducativos.

Palabras clave: Identidad profesional; Manuales escolares; España democrática; Mujeres; Educación Primaria.

Abstract. The construction of professional identity is a concept that holds interest for a variety of disciplines such as Anthropology, Psychology or Pedagogy. From the perspective of social constructivism, it has a narrative, dynamic character and is shaped by the interaction of the subject with current socio-historical discourses and their interiorization. During the decade of the nineteen seventies, the labor market in Spain experienced a massive incorporation of women, brought about by social and legislative advances in education and employment. Such progress linked to the changes caused by the establishment of democracy were and still are essential in the configuration and renewal of female identity in the economic field. This article focuses on the influence of the school textbook — the main didactic resource used in formal education - in this configuration. It could portray role models and gender stereotypes with a potential influence on the transmission and configuration of a biased socio-labor culture. In order to study this influence, our research examines a total of 20 elementary education textbooks in the areas of Language and Social Sciences in two periods of democratic Spain - the so-called Transition period and the current moment-, to explore the professional identity of women linked to the economic socialization as this is conveyed through this educational tool. Our results reveal a minimal inclusion of women as economic subjects in the textbooks; the underrepresentation of females performing paid activities, as well the lack of professional diversity serve to highlight a substantial inequality in the socialization processes between men and women, contrary to the goals of coeducational teaching values.

Keywords: Professional identity; Textbooks; Democratic Spain; Women; Elementary Education. 


\section{INTRODUCCIÓN}

Una de las grandes cuestiones que siempre ha interrogado al ser humano es aquella que apela a su propio ser, a su original constitución como individuo, como persona única y diferente de todas las demás. La literatura reciente ha reformulado dicho interrogante en términos de construcción de identidad y desde la antropología, la epistemología, la ética, la sociología, la psicología y, por supuesto, la educación, se ha intentado proporcionar explicaciones satisfactorias. Estas disciplinas coinciden en rechazar la identidad personal como un concepto homogéneo y estable, poniendo en valor su carácter distribuido y dialógico. Es vista como «un enjambre de participaciones $»^{2} \mathrm{O}$ "una suma de pertenencias», ${ }^{3}$ producto de las situaciones en las que el ser humano actúa y que la dotan de contenido. La identidad emerge y se reconfigura a través de relaciones en continuo cambio. ${ }^{4}$ Se sustenta en unos significados, lenguajes y discursos que son cultural e históricamente específicos referidos a género, educación, estatus profesional, éxito vital, etc. ${ }^{5}$ Estos proporcionan al sujeto un modo de interpretación y de dar sentido al mundo y a las personas que viven en él. ${ }^{6}$

Entre las propiedades más valiosas del «yo» encontramos su estructura narrativa —el self historiado de Bruner; 7 la identidad narrativa de Ricoeur-; 8 esto es, el sujeto se define a sí mismo, cuenta cómo se autopercibe, a través de una serie de historias que emplean los elementos de la narrativa. Tal como indican Santamaría y Martínez la narración puede considerarse el recurso que posibilita la existencia de

\footnotetext{
2 Jerome Bruner, "Meaning and Self in Cultural Perspective», en The social self, eds. David Bakhurst y Christine Sypnowich (Londres: Sage, 1996), 18-30.

3 Amin Maalouf, Identidades asesinas (Madrid: Alianza editorial, 1999).

${ }_{4}$ Kenneth J. Gergen, Realities and relationships: Soundings in social construction (Cambridge: Harvard University Press, 1994).

5 Bruner, «Meaning and Self».

6 Burr, An introduction to social constructionism.

7 Jerome Bruner, Acts of Meaning (Cambridge: Harvard University Press, 1990).

${ }^{8}$ Paul Ricoeur, Sí mismo como otro (Madrid: Siglo XXI, 1996).
} 
un «yo» percibido como continuo y coherente. ${ }^{9}$ Nos narramos a nosotros mismos cómo hemos llegado al presente y damos a este un significado. También, en nuestra narración, nos proyectamos hacia el futuro, incluyendo deseos, ilusiones, expectativas, esperanzas. Estos elementos son mediados por instrumentos semióticos de los que el individuo se apropia durante su vida a través de su participación en distintos escenarios socioculturales, por lo que se recogen de los modelos culturales y discursos sociales a los que está expuesto el sujeto —valores, estereotipos, roles de género...-. En concreto, destacamos el poder de los estereotipos, ideas colectivas fuertemente arraigadas y preconcebidas que determinan cómo han de comportarse las personas, qué características son adecuadas a tenor del grupo social al que pertenezcan, género, religión, etc., sirviendo de referente para estructurar la identidad de los sujetos. ${ }^{10}$ En este sentido, los estereotipos poseen una función prescriptiva referida a «lo que debe ser y lo que debe hacerse». ${ }^{11}$

La experiencia escolar supone uno de los hitos más significativos en la configuración de nuestra identidad, al formar un eje vertebrador de prácticas, comportamientos y actitudes. Dentro del contexto educativo, la presente investigación profundiza en la influencia de la socialización económica transmitida desde los libros de texto en la construcción de la identidad profesional de las niñas; sin olvidar, por supuesto, que la identidad personal se ve afectada por la posición que cada niña o niño ocupa en los distintos subsistemas o categorías y, por tanto, las expectativas laborales se conformarán de modo diferente, también en función de otras variables como la clase social, la etnia o la edad.

La identidad profesional femenina se compone de un conjunto de atributos que permiten a las mujeres reconocerse a sí mismas como

\footnotetext{
9 Andrés Santamaría y Miguel Ángel Martínez, «La construcción de significados en el marco de un Psicología Cultural: el pensamiento narrativo», en Vygotski en la psicología contemporánea, comps. Mercedes Cubero y Juan Daniel Ramírez (Buenos Aires: Miño y Dávila, 2015), 167-193.

10 Pilar Colás y Patricia Villaciervos, «La interiorización de los estereotipos de género en jóvenes y adolescentes», Revista de Investigación Educativa 25, no. 1 (2007): 58.

11 Esther Barberá, «Perspectiva cognitivo-social: estereotipos y esquemas de género», en Psicología y Género, coords. Esther Barberá, Isabel Martínez y Amparo Bonilla (Madrid: Pearson Prentice Hall, 2004), 55-80.
} 
integrantes de un gremio profesional. Desde la masiva incorporación de la mujer al mundo laboral durante la Transición política española hasta la España de hoy en día, persiste una segregación horizontal y vertical en el mundo laboral que aleja a las mujeres de determinados puestos de trabajo y de posiciones de poder. Son años de desarrollo democrático en los que hemos centrado nuestra mirada en los manuales escolares, desde los cuales las niñas empiezan a recibir mensajes acerca de dónde se sentirán más cómodas en el trabajo, cuál es su sitio en el mercado laboral, etc.

Estudios previos en manualística escolar han revelado la pervivencia de creencias sexistas en torno al papel de la mujer en la sociedad, ${ }^{12}$ pero muy pocos han analizado exhaustivamente su representación en el plano laboral. En nuestro artículo, presentamos un marco teórico que describe el contexto laboral de las españolas desde la Transición hasta la actualidad, con especial atención a los avances sociales, legislativos y educativos logrados y a los obstáculos aún sin resolver. Seguidamente, hemos dedicado un epígrafe al papel que juegan los manuales en la socialización diferencial de hombres y mujeres. Por último, se exponen los principales resultados de nuestra investigación, planteando reflexiones transversales que podrían sensibilizar al profesorado sobre la importancia de analizar y realizar una buena selección de los recursos didácticos empleados en el aula basada en principios de igualdad y coeducación.

\section{LA INCORPORACIÓN FEMENINA AL MUNDO LABORAL EN LA ESPAÑA DEMOCRÁTICA}

La muerte de Francisco Franco en noviembre de 1975 supuso un hecho fundamental en la historia española más reciente. Tras cuatro décadas de dictadura, el país comenzó su andadura hacia un nuevo sistema político: la democracia. Los primeros años comprenden lo que se ha denominado «Transición», cuya extensión temporal más generalizada sitúa

\footnotetext{
12 A este respecto véase: Nuria Garreta y Pilar Careaga, Modelos masculinos y femeninos en los textos de EGB (Madrid: Instituto de la Mujer, 1987); Nieves Blanco, "Análisis de materiales curriculares», en Mujer y educación una perspectiva de género, ed. Ana Vega (Málaga: Ediciones Aljibe, 2007), 105115; Ana López-Navajas, «Las mujeres que nos faltan: análisis de la ausencia de las mujeres en los manuales escolares» (Tesis doctoral, Universitat de València, 2015).
} 
su inicio en 1975 y su final en 1982, con la victoria por mayoría absoluta del Partido Socialista Obrero Español (PSOE), encabezado por Felipe González Márquez, en las elecciones generales. Muchos son los sucesos de relevancia histórica que tuvieron lugar durante la Transición —-Ley de Amnistía (1977), Pactos de la Moncloa (1977), aprobación de la Constitución Española en 1978, etc.-, pero nos centraremos en las transformaciones acaecidas en el ámbito laboral que afectaron principalmente a las mujeres.

El periodo de la Transición política supuso un marco propicio para las trabajadoras, traducido en un significativo ingreso y una fuerte participación y visibilidad femenina en el mercado profesional. En 1975 se celebró el Año Internacional de la Mujer, convocado por la Organización de las Naciones Unidas, que dio lugar a la organización de dos jornadas significativas para el devenir del movimiento de las mujeres en España: las Primeras Jornadas por la Liberación de la Mujer y las Primeres Jornades Catalanas de la Dona. En ellas, se reivindicaron la igualdad salarial y de acceso a los cargos de responsabilidad en el empleo, la creación de guarderías infantiles y la aceptación de la condición de la mujer trabajadora en la lucha del movimiento obrero. ${ }^{13}$ Algunas de estas demandas empezaron a ser recogidas por acciones institucionales y legislativas. ${ }^{14}$ Una de las primeras fue la Ley 16/1976, de 8 de abril, de Relaciones Laborales que legitimó que mujeres y hombres, al poseer la misma capacidad laboral, debían tener los mismos derechos, obligaciones y oportunidades (artículo 10). ${ }^{15}$ No obstante, el hito más importante de la Transición fue la promulgación de la Constitución Española de 1978, que sentó las bases de una evolución política hacia una democracia parlamentaria transformadora de desigualdades sociales, políticas, económicas, laborales y culturales. El Estado, mediante sus poderes públicos, se comprometió en su artículo 9.2 y 14 a garantizar la plena

\footnotetext{
${ }^{13}$ Luis Alberto Cabrera, Mujer, trabajo y sociedad (1839-1983) (Madrid: Fundación Francisco Largo Caballero, 2005).

14 Pilar Folguera, «Integrando el género en la agenda política. Feminismo, Transición y democracia», en 100 Años en femenino. Una historia de mujeres en España, eds. Isabel Tejeda y María O. Rubio (Madrid, Asociación Cultural Española Conde Duque, 2012), 99.

15 «Ley 16/1976, de 8 de abril, de Relaciones Laborales», Boletín Oficial del Estado, 96, de 21 de abril (1976): 7896. https://www.boe.es/buscar/doc.php?id=BOE-A-1976-8373
} 
igualdad, sin discriminación alguna por razón de sexo. ${ }^{16}$ Centrándonos en el terreno laboral, el artículo 35 proclamó el derecho a la libre elección profesional y a la recepción de una remuneración digna tanto para hombres como para mujeres. Dos años más tarde, la Ley 8/1980, de 10 de marzo, del Estatuto de los Trabajadores reiteró, en su artículo 17, el derecho de toda la ciudadanía a formarse y elegir un oficio, y en su artículo 28 el principio de igualdad salarial. ${ }^{17}$

Al mismo tiempo, cambios sociales y demográficos — descenso de la natalidad, retraso de la edad del matrimonio, interés por la formación y realización profesional de las mujeres, concienciación promovida por la segunda ola del feminismo...- facilitaron, a finales de la década de los setenta, la fuerte entrada de las españolas al mercado de trabajo. La tercerización de la economía, propia del interés por materializar el Estado de bienestar, incentivó dicha incorporación al implicar la creación de una gran cantidad de empleos considerados «adecuados» a su condición femenina. ${ }^{18}$ La proporción de la tasa de actividad femenina en los diferentes sectores económicos evolucionó y quedó repartida de la siguiente forma durante la Transición política (véase tabla 1).

\footnotetext{
${ }^{16}$ La aprobación de la Constitución española supuso cierta disconformidad en el movimiento feminista. Diferentes estudios discuten la falta de consideración de las mujeres en su proceso constituyente, argumentando que en la Constitución no se vieron reflejadas las necesidades que venían siendo reivindicadas por el feminismo español - Movimiento Democrático de Mujeres, entre otras organizaciones-. Puede consultar: Soraya Gahete, «Las luchas feministas. Las principales campañas del movimiento feminista español (1976-1981)», Investigaciones feministas 8, no. 2 (2017): 584. Como consecuencia, se denunció una falta de compromiso institucional respecto a los derechos y libertades de las mujeres que tuvieron que ser abarcadas en medidas legislativas posteriores. Nos referimos a cuestiones olvidadas relacionadas con el artículo 15 de derechos fundamentales a la vida y a la integridad física y moral de las mujeres como el divorcio, el aborto, o la violencia contra las mujeres. A este respecto consulte: María Luisa Balaguer, Mujer y Constitución: La construcción jurídica del género (Madrid: Ediciones Cátedra, 2005).

17 «Ley 8/1980, de 10 de marzo, del Estatuto de los Trabajadores», Boletín Oficial del Estado, 64, de 14 de marzo (1980): 5799-5815. https://www.boe.es/buscar/doc.php?id=BOE-A-1980-5683

18 Ana María Porto, «La mujer en el siglo XXI y el oficio del matrimonio», en Cuestiones actuales sobre el trabajo de la mujer y su protección social, eds. Asunción López-Arranz, Cristina Faraldo y María del Pilar Millor (Valencia: Tirant lo Blanch, 2010), 13-36; Mónica Moreno-Seco, «Sexo, Marx y Nova Cançó. Género, política y vida privada en la juventud comunista de los años setenta», Historia Contemporánea 54 (2017): 47-84.
} 
Tabla 1. Tasa de actividad femenina por sectores económicos durante la Transición política

\begin{tabular}{ccc}
\hline & $\mathbf{1 9 7 6}$ & $\mathbf{1 9 8 2}$ \\
\hline Agricultura & $21,36 \%$ & $16,14 \%$ \\
Industria & $32,67 \%$ & $18,63 \%$ \\
Construcción & $0,84 \%$ & $0,63 \%$ \\
Servicios & $54,13 \%$ & $64,61 \%$ \\
\hline
\end{tabular}

Fuente: elaboración propia a partir del INE.19

Al comparar dicha actividad económica con la masculina encontramos evidentes desigualdades. Siguiendo los datos proporcionados por el Instituto Nacional de Estadística (INE), la tasas de actividad de los varones fue de un 77,8\% en 1976 y 72,94\% en 1982, mientras que la femenina alcanzó el 28,67\% en 1976 y 27,89\% en $1982 .{ }^{20}$ En relación a este punto, autores como Bautista señalan la persistencia de posturas tradicionales y resistentes hacia el empleo femenino, ${ }^{21}$ generando un desequilibrio entre los avances formales producidos y los reales. ${ }^{22}$ La concepción aún conservadora del rol femenino, unida a la falta de ayudas a la conciliación familiar, dificultaban a muchas mujeres compatibilizar sus empleos con las labores domésticas y de crianza, convirtiéndose en el principal motivo de renuncia a sus puestos de trabajo.

Finalizado el período de Transición, quedaba aún mucho camino por recorrer en cuanto a igualdad de acceso y oportunidades en el mundo laboral para las féminas. Sin duda, un logro a destacar fue la creación del Instituto de la Mujer con la finalidad de promover y analizar el éxito del desempeño de las políticas públicas relacionadas con la participación

\footnotetext{
19 Instituto Nacional de Estadística, «Encuesta de población activa». http://www.ine.es/dyngs/INEbase/ es/operacion.htm?c=Estadistica_C\&cid=1254736176918\&menu=resultados\&idp=1254735976595 (consultado el 7-4-2019)

${ }^{20} \mathrm{INE}$, «Encuesta de población activa».

${ }^{21}$ Esperanza Bautista, «Mujer y democracia en España: evolución jurídica y realidad social», Documentación Social 105 (1996): 49-73.

22 Según el Informe de la Fundación Foessa de 1976, el 82,3\% de los varones y el 38,7\% de las mujeres en España asignaban íntegramente a las mujeres las responsabilidades del trabajo doméstico y el cuidado de los hijos/as. Fundación Foessa, Estudios sociológicos sobre la situación social de España, 1975 (Madrid: Euroamérica S.A., 1976), 372.
} 
laboral, política, social, económica y cultural de las mujeres, para prevenir toda clase de discriminación por razones de sexo. ${ }^{23}$ Años más tarde, las Comunidades Autónomas comenzaron a contar con su propio Instituto, centros con un peso fundamental en la elaboración y consecución de los Planes para Igualdad de Oportunidades de las Mujeres desde 1988 hasta nuestros días.

El ingreso de España a la Comunidad Económica Europea en 1986 favoreció la concienciación sobre la necesidad de luchar a favor de la eliminación de todo tipo de limitaciones por cuestiones de sexo. Para ello, era preciso continuar promoviendo una legislación adecuada. Un claro ejemplo lo encontramos en el Tratado de Ámsterdam de 1997 que incluía la transversalidad mainstreaming de género ${ }^{24}$ y el objetivo de suprimir las desigualdades de género especialmente en el mercado laboral (artículos 2 y 118).25 Al amparo de este fin, España pretendía favorecer la corresponsabilidad entre mujeres y hombres mediante la Ley 39/1999 de 5 de noviembre. ${ }^{26}$ Dicha ley extendió el permiso de reducción de jornada por causas familiares y el periodo de baja paternal al varón (artículos 2 y 5), y prohibió la anulación del contrato de la mujer trabajadora por motivo de embarazo (artículo 7.2). Por último, entre otras medidas, merece mención especial la Ley Orgánica 3/2007, de 22 de marzo, para la igualdad efectiva de mujeres y hombres, pionera en incorporar el principio de igualdad de género en España en todos los ámbitos de la vida (económica, laboral, cultural, social, política, civil...). ${ }^{27}$

23 «Ley 16/1983, de 24 de octubre, de creación del Organismo Autónomo Instituto de la Mujer», Boletín Oficial del Estado, 256, de 26 de octubre (1983): 28936-28937. https://www.boe.es/buscar/doc. php?id=BOE-A-1983-28126

${ }^{24}$ Juana M. Gil, «Repensando la constitución: Una mirada al deber de trabajar y al derecho al trabajo», Revista de Derecho Político 104 (2019): 65.

25 «Tratado de Amsterdam por el que se modifican el Tratado de la Unión Europea, los Tratados constitutivos de las Comunidades Europeas y determinados actos conexos, de 2 de octubre de 1997», Diario Oficial de las Comunidades Europeas, 97/C340/01, 10 de noviembre (1997): 24-38. https://www. ecb.europa.eu/ecb/legal/pdf/amsterdam_es.pdf

26 «Ley 39/1999, de 5 de noviembre, para Promover la Conciliación de la Vida Familiar y Laboral de las Personas Trabajadoras», Boletín Oficial del Estado, 266, de 6 de noviembre (1999): 38936-38937. https://www.boe.es/buscar/doc.php?id=BOE-A-1999-21568

27 «Ley Orgánica 3/2007, de 22 de marzo, para la igualdad efectiva de mujeres y hombres», Boletín Oficial del Estado, 71, de 23 de marzo (2007): 12611-12645. https:/www.boe.es/buscar/doc.php?id=BOE-A-2007-6115 
La legislación española ha puesto en marcha considerables esfuerzos para luchar por una igualdad que, hoy en día, es formal pero no real. Desgraciadamente, persisten desigualdades laborales, sociales y educativas muy significativas que afectan a muchas mujeres. ${ }^{28}$ Uno de los elementos clave en nuestro estudio es la proporción de mujeres y hombres en los distintos sectores económicos. Al respecto, las autoras Cristina Borderías y Lina Gálvez-Muñoz destacan la construcción histórica del modelo de división sexual del trabajo, en el cual las mujeres han sido tradicionalmente asignadas a determinados sectores productivos concretos -industria tabaquera, conservera, textil, sector servicios...-, ocupando empleos muy precarios y de menor prestigio social, lo que tiene un enorme peso en los mercados actuales, ${ }^{29}$ donde continua presente este desequilibrio (véase gráfico 1). ${ }^{30}$ Con independencia de esta notable segregación ocupacional, la tasa de actividad económica de las mujeres no ha parado de ascender en los últimos años, llegando a alcanzar en el año 2018 un 53,05\%.31

Gráfico 1. Porcentajes de los activos por sector económico y sexo en 2018

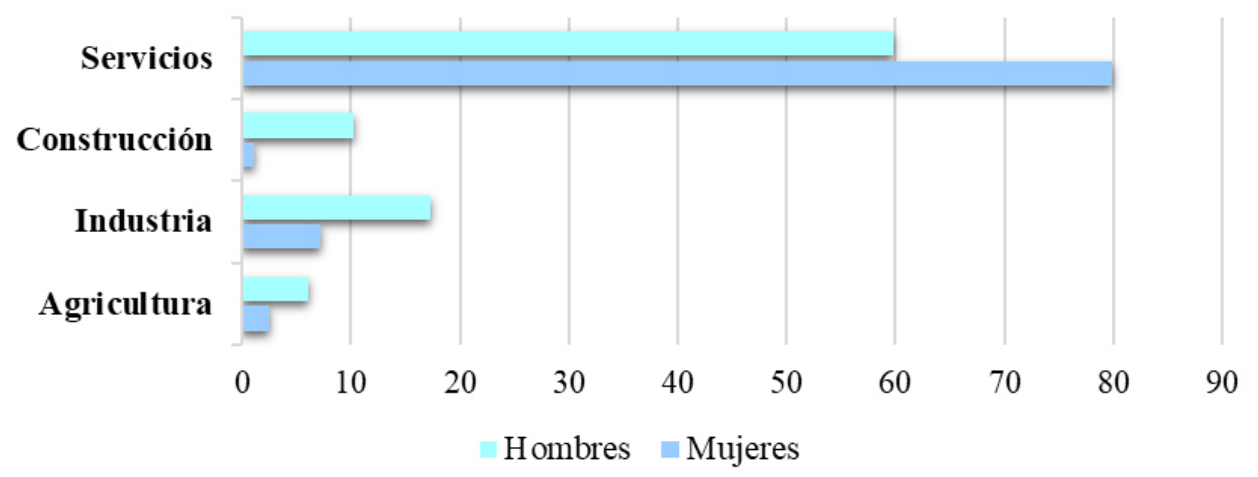

Fuente: elaboración propia.

\footnotetext{
${ }_{28}$ Carlos Usabiaga et al., La segregación laboral de la mujer andaluza: Indicadores, consecuencias y medidas hacia la igualdad de género (Sevilla: Fundación Pública Andaluza Centro de Estudios Andaluces, 2014).

${ }_{29}$ Cristina Borderías y Lina Gálvez-Muñoz, «Cambios y continuidades en las desigualdades de género. Notas para una agenda de investigación», Areas: Revista Internacional de Ciencias Sociales 33 (2014): 7-15.

${ }^{30}$ Instituto Nacional de Estadística, «Distribución porcentual de los activos por sector económico y sexo». https://www.ine.es/jaxiT3/Tabla.htm?t=3969\&L=0 (consultado el 18-6-2019).

${ }^{31}$ INE, «Encuesta de población activa».
} 
Las desigualdades de género en España también se hacen visibles en el tipo de jornada laboral. Las mujeres ocupan con más frecuencia empleos a tiempo parcial $(25,44 \%),{ }^{32}$ y entre sus principales motivos se destaca el cuidado de menores y adultos enfermos, incapacitados o mayores. ${ }^{33}$ En España en el año 2017 el 92,34\% de las excedencias por cuidado de hijos/as y el $83,66 \%$ por cuidados de familiares dependientes fueron solicitadas por mujeres, persistiendo una falta de corresponsabilidad familiar. ${ }^{34}$ Estas cifras son altamente reveladoras: demuestran que no se trata de una decisión puntual, voluntaria y personal de las mujeres, sino que forma parte de nuestra cultura laboral y asienta sus raíces en nuestro sistema patriarcal y capitalista. ${ }^{35}$ Las féminas quedan socialmente responsables de la exigente y desvalorizada economía de cuidados. ${ }^{36}$ Un mandato y trampa patriarcal que Juana M. Gil denomina «el amor de casa» ${ }^{37}$ y Cristina Carrasco «la mística del cuidado»,38 un autosacrificio universalmente «deseado» por las mujeres inculcado desde los procesos de socialización. Esto tiene una enorme repercusión sobre la vida de las mujeres, que se agrava dada la situación sociocultural actual, comúnmente llamada «crisis de los cuidados» —nuevos modelos de familias, inversión de la pirámide demográfica, elevado coste de servicios de atención a personas dependientes, etc.- ${ }^{39}$ La gran carga mental, física y afectiva que soportan las mujeres son elementos que repercuten en la promoción de las trabajadoras. Hablamos de

\footnotetext{
32 INE, «Encuesta de población activa».

33 Instituto Nacional de Estadística, «Razones del trabajo a tiempo parcial según grupos de edad en España». https://www.ine.es/jaxiT3/Tabla.htm?t=13583 (consultado el 8-4-2019).

34 Instituto de la Mujer y Para la Igualdad de Oportunidades, «Mujeres en Cifras: Conciliación, Excedencias, permisos y reducciones de jornadas». http://www.inmujer.gob.es/MujerCifras/Conciliacion/ExcedPermisos.htm (consultado el 29-12-2019).
}

35 Teresa Torns, «Conciliación de la vida laboral y familiar o corresponsabilidad: ¿El mismo discurso?», RIDEG: revista interdisciplinar de estudios de género 1 (2011): 6.

36 Es fundamental reconocer el trabajo doméstico desde una economía feminista. Véase: Teresa Torns. «El trabajo y el cuidado. Cuestiones teórico-metodológicas desde la perspectiva de género», Empiria: Revista de metodología de ciencias sociales 15 (2008): 56.

37 Gil, «Repensando la constitución», 65.

38 Cristina Carrasco, "El cuidado como eje vertebrador de una nueva economía», Cuadernos de Relaciones Laborales 31, no. 1 (2013): 49.

39 Yayo Herrero, "Miradas ecofeministas para transitar a un mundo justo y sostenible», Revista de economía crítica 16 (2013): 278-307; Tindara Addabbo et al., Gender Inequalities, Households and the Production of Well-Being in Modern Europe (Londres: Routledge, 2010). 
tiempos y energías que permanecen encubiertos debido a su interesada relación con el sistema capitalista. ${ }^{40}$ Por consiguiente, a pesar de los avances jurídicos y laborales para las españolas, hemos de recalcar que quedan obstáculos por salvar: el conocido "techo de cristal», ${ }^{41}$ término que se refiere a las barreras que sufren las mujeres que desempeñan o aspiran a ejercer altos cargos (únicamente el 31\% de los cargos directivos son ocupados por mujeres), o la brecha salarial (14,9\% en España). ${ }^{42}$

Entre las causas de estos desequilibrios en el mundo laboral, los estereotipos de género tienen un gran peso, ya que «crean hábitos que influyen en las actitudes de la población en general y de los empresarios en particular». ${ }^{43}$ Estos juicios de valor están altamente influenciados por la educación que reciben desde diferentes agentes de su entorno - profesorado, familiares, medios de comunicación, recursos educativos, etc.-.${ }^{44}$ Se ha estudiado que desde Educación Primaria el alumnado muestra graves prejuicios respecto a las capacidades intelectuales y competencias femeninas de sus iguales, lo que afecta especialmente a la autoestima de las chicas, reflejándose en la vida adulta en relación a sus contribuciones profesionales. ${ }^{45}$ De este modo, se ha

\footnotetext{
40 Carrasco, «El cuidado como eje», 45.

41 Carol Hymowitz y Timothy D. Schellhardt, «The glass ceiling: Why women can't seem to break the invisible barrier that blocks them from top jobs», The Wall Street Journal 24, no. 1 (1986): 157392.

42 Eurostat, «The life of women and men in Europe: A statistical portrait». https://ec.europa.eu/eurostat/cache/infographs/womenmen/ (consultado el 14-2-2019).
}

43 Alfonso Alba, La riqueza de las familias: Mujer y mercado de trabajo en la España democrática. (Barcelona: Ariel, 2000), 108.

${ }_{44}$ Racgek S. Pienta y Ann M. Smith, «Women on the margins: The politics of gender in the language and content of science textbooks", en The new politics of the textbook: Problematizing the portrayal of marginalized groups in textbooks, eds. Heather Hickman y Brad Porfilio (Rotterdam: Sense Publishers, 2012), 49-68.

45 Consulte: Lin Bian, Sarah-Jane Leslie y Andrei Cimpian, «Evidence of bias against girls and women in contexts that emphasize intellectual ability», American Psychologist 73, no. 9 (2018): 11391153. Un reciente estudio de la Universidad de Yale determinó que las mujeres científicas subestiman su trabajo, teniendo una gran repercusión en su promoción profesional. Marc Lerchenmueller, Olav Sorenson y Anupam B. Jena, "Gender differences in how scientists present the importance of their research: Observational study», The BMJ 367, no. 16573 (2019): 1-8. Este hecho podría vincularse, además, con el llamado «sentimiento de pertenencia femenino» especialmente vulnerable en ámbitos estereotipados tradicionalmente como «ajenos a su género» como el ámbito de las carreras STEM —Ciencia, Tecnología, Ingeniería y Matemáticas-. Charlotta Magnusson y Magnus Nermo, «From childhood to young adulthood: the importance of self-esteem during childhood for 
demostrado la importancia que tiene para las niñas y las mujeres ser reconocidas y valoradas socialmente, y tener referentes hacia los que poderse proyectar. Creemos que, para romper estas brechas de género, se precisa de la actuación docente. En esta labor profesional centramos nuestro objeto de estudio en el currículum escolar y, en concreto, en la socialización económica transmitida mediante los libros de texto, que pueden presentar fuertes estereotipos unidos a una cultura sociolaboral sesgada y discriminatoria. ${ }^{46}$ Dichas concepciones poseen una elevada influencia en edades tempranas y pueden limitar las concepciones e intereses, especialmente de las niñas, sobre sus aspiraciones profesionales.

\section{LA MANUALÍSTICA ESCOLAR Y SU INFLUENCIA EN EL PROCESO DE SOCIALIZACIÓN DIFERENCIAL}

Los libros de texto, dado su uso generalizado, son una de las principales fuentes de conocimiento en el sistema educativo. A diario, innumerables docentes emplean este recurso didáctico para planificar sus sesiones. Su uso se sostiene sobre una fina y frágil línea entre la «orientación» y la «restricción», lo que produce que, con frecuencia, determine exclusivamente los contenidos a trabajar en lugar de servir como material de ayuda o guía en el proceso de enseñanza-aprendizaje. ${ }^{47}$ Nos referimos a que una parte significativa del profesorado permanece con una actitud pasiva, no elige qué contenidos enseñar, sino que se deja llevar por los previamente establecidos por las empresas editoriales. Ahora bien, a veces se olvida que el manual escolar no es una simple herramienta de difusión, sino también de poder y que propaga los «saberes legítimos»en

occupational achievements among young men and women», Journal of Youth Studies 21, no. 10 (2018): 1392-1410.

${ }^{46}$ En el caso de niños y niñas, nos referimos por «cultura sociolaboral» al conocimiento de la situación económica del país, de los derechos y deberes de las personas trabajadoras, del tipo de profesiones presentes en la sociedad, las habilidades necesarias para su desempeño, etc., adecuado a su edad. Esta podría considerarse «sesgada y discriminatoria» porque se difunden, mediante los manuales, mensajes distintos por cuestiones de género respecto a su papel en el terreno laboral, como se expondrá a lo largo del artículo.

47 Dionysios Gouvias y Christos Alexopoulos, «Sexist stereotypes in the language textbooks of the Greek primary school: a multidimensional approach», Gender and Education 30, no. 5 (2018): 642662. 
diferentes ámbitos, no solo en el disciplinar. ${ }^{48}$ En el plano que nos ocupa, las nociones socioculturales respecto al género son transmitidas a partir de este recurso, derivando en una serie de conductas, características, valores e ideas respecto a lo que es apropiado o esperado de mujeres y hombres en una determinada comunidad,49 conformando los denominados «estereotipos de género». ${ }^{50}$ Mediante los libros de texto, el alumnado establece su propia visión de la realidad, y al mismo tiempo construye su identidad, intentando encajar en los modelos que en ellos se proponen. ${ }^{51}$

Entendiendo el género como el conjunto de características sociales, culturales, políticas, psicológicas, jurídicas y económicas que la sociedad asigna de forma diferenciada como propias de un género u otro, es fácil detectar que supone una construcción sociocultural. ${ }^{52} \mathrm{Si}$ analizamos ese conjunto de rasgos asignado por la comunidad a cada género desde una perspectiva de género descubrimos que no tiene nada de

\footnotetext{
48 Juan Carlos Bel, «Imagen y libros de texto de Historia en educación primaria: Estudio comparativo a partir de un análisis cualitativo", Revista de Educación 377 (2017): 82-112.; Alain Choppin, «L'histoire des manuels scolaires: une approche globale», Histoire de l'Education 9 (1980): $1-25$.

49 Tiziana Ramaci et al., "Gender stereotypes in occupational choice: a cross-sectional study on a group of Italian adolescents», Psychology Research and Behavior Management 10 (2017): 109-117.

${ }^{50}$ La autora Caro define los estereotipos de género como: «Construcciones culturales que determinan una visión de las características y actitudes de cada sexo. Crean modelos rígidos en los que tienen que encajar para ser socialmente aceptado [...] visión tópica construida, establecen un sistema desigual de relaciones entre los dos sexos y cada uno de ellos hacia el mundo» (Caro, 2008:226). Coral Caro, «Un amor a tu medida. Estereotipos y violencia en las relaciones amorosas», Revista de Estudios de Juventud 83 (2008): 213-228.
}

51 Fatemeh Parham, «Gender Representation in Children's EFL Textbooks», Theory and Practice in Language Studies 3, no. 9 (2013): 1674-1678; Ali Salami y Amir Ghajarieh, «Culture and Gender Representation in Iranian School Textbooks», Sexuality \& Culture 20 (2016): 69-84. No debemos olvidar la influencia de otros medios de comunicación en el fenómeno de identificación personal —cine, televisión, redes sociales, etc.- los cuales poseen claros componentes morales e ideológicos que deben ser abordados desde perspectivas multidisciplinares y que serán examinados en un futuro en nuestra investigación, al ser un excepcional recurso para observar la coherencia entre los distintos discursos económicos en torno a la socialización laboral femenina. Sin embargo, en este artículo profundizamos en el contexto escolar en el que se estima que el manual escolar condiciona de manera importante el tipo de enseñanza que se transmite a los niños y niñas. Consulte: M. Pilar Fernández y Presentación A. Caballero, «El libro de texto como objeto de estudio y recurso didáctico para el aprendizaje: fortalezas y debilidades», Revista Electrónica Interuniversitaria de Formación del Profesorado 20, no. 1 (2017): 201-217; Arthur Parcerisa, Materiales curriculares: cómo elaborarlos, seleccionarlos y usarlos (Barcelona: Grao, 1996), 35.

52 Iria Marañón, Educar en el feminismo (Barcelona: Plataforma editorial, 2008). 
innato o natural; ${ }^{53}$ el sujeto los adquiere mediante la socialización, y son susceptibles de modificaciones, revisiones y críticas. ${ }^{54}$ Tradicionalmente en la concepción androcéntrica de nuestra sociedad, los hombres han sido estereotipadamente orientados al trabajo en la esfera pública, potenciándose el desarrollo de actitudes basadas en la competitividad, el control, la asunción de riesgos, etc. En cambio, las mujeres han sido encasilladas en el ámbito privado, donde debían desempeñar actividades dirigidas a satisfacer el mandato cultural impuesto en la sociedad: «estar disponibles para atender y cuidar a los demás», validando competencias afectivas y emocionales. ${ }^{55}$ Los roles prefijados por género han originado una división sexual del trabajo donde las mujeres salen perjudicadas en cuanto a salario y reconocimiento social pues sus tareas, en una sociedad patriarcal, son consideradas de segunda categoría. ${ }^{56} \mathrm{Se}$ llega a hablar de profesiones «feminizadas» $\mathrm{y}$ «masculinizadas», debido al alto porcentaje de un colectivo u otro ejerciéndolas, que se ha vinculado a su vez con una desigualdad de intereses o motivaciones por trabajar con «personas» $\mathrm{o}$ «cosas» por parte de las mujeres, en el primer caso, y de los hombres, en el segundo — preferencia que se «vende» como «natural»—. ${ }^{57}$ Los empleos feminizados se ligan fundamentalmente al ámbito social o humanístico (enfermería, magisterio...), y los masculinizados con el sector de la producción, gestión de las organizaciones, labores científicas y técnicas, etc. ${ }^{58}$

En el terreno de la manualística, trabajos previos han desvelado manifestaciones de sexismo en el tipo de lenguaje utilizado, en la omisión

\footnotetext{
53 Marcela Lagarde, Género y feminismo: Desarrollo humano y democracia (Madrid: Horas y Horas, 1996).

54 María José Urruzola, «La educación de las relaciones afectivas y sexuales», Aula de innovación educativa 91 (2000): 30-31.

55 Marina Subirats, «De la escuela mixta a la coeducación. La educación de las niñas: el aprendizaje de la subordinación», en Mujer y educación una perspectiva de género, ed. Ana Vega (Málaga: Ediciones Aljibe, 2007), 137-147.

56 Eva Cifre et al., «Sex, Gender Identity, and Perceived Employability among Spanish Employed and Unemployed Youngsters», Frontiers in Psychology 9, no. 2467 (2018): 1-12.

57 William G. Graziano, Meara M. Habashi y Demetra Evangelou, «Orientations and motivations: Are you a "people person", a "thing person”, ¿'or both?», Motivation and Emotion 36 (2012): $465-477$.

58 Isabel M. Vázquez y Ángeles Blanco-Blanco, «Factores sociocognitivos asociados a la elección de estudios científico-matemáticos. Un análisis diferencial por sexo y curso en la Educación Secundaria», Revista de Investigación Educativa 37, no. 1 (2019): 269-286.
} 
de personajes y logros femeninos, y en la infrarrepresentación y desvalorización de las mujeres. ${ }^{59}$ En esta investigación, centramos nuestra atención en los patrones masculinos y femeninos expuestos en los libros de texto relacionados con el mundo laboral. Anteriores estudios han descubierto que desde este material se presenta una fuerte discriminación laboral hacia las féminas, ofreciéndoles un número muy limitado de opciones profesionales, que suelen tener poco reconocimiento social y remuneración económica, además de estar restringidos al ámbito de los cuidados y tareas domésticas, es decir, a los espacios privados y al sector servicios. ${ }^{60}$ Por tanto, se pone en juego una evidente división sexual del trabajo que es justificada mediante estereotipos como la incuestionable asignación de cualidades a las mujeres como la sensibilidad, la bondad, la sumisión, la pasividad, la dependencia o la preocupación por el bienestar de los demás, que convierte a los personajes femeninos en más «afines» a la ejecución de dichos roles. En contraposición, las virtudes «masculinas» como la competitividad, la autoridad o la inteligencia, proporcionan a los personajes varones un perfil profesional mucho más extenso. ${ }^{61}$ Como consecuencia de esta representación desigual, el alumnado, utilizando este recurso educativo, accede y puede construir un imaginario socio-laboral sesgado y jerárquico en el que las niñas se ven restringidas a modelos muy estandarizados y repetitivos que difícilmente representan el alcance real y el potencial de las mujeres. En este marco teórico se encuadra nuestra investigación que, dentro de los estudios de género o estudios de las mujeres -Women's Studies-, es novedosa puesto que pocos estudios en manualística escolar han profundizado en el campo de la socialización económica. ${ }^{62}$

\footnotetext{
59 Garreta y Careaga, Modelos masculinos y femeninos en los textos de EGB; Blanco, "Análisis de materiales curriculares»; López-Navajas, «Las mujeres que nos faltan».

${ }_{60}$ Nieves Blanco, El sexismo en los materiales educativos de la E.SO (Sevilla: Instituto Andaluz de la Mujer, 2000); Kazi Md. Mukitul Islam y M. Niaz Asadullah, «Gender stereotypes and education: A comparative content analysis of Malaysian, Indonesian, Pakistani and Bangladeshi school textbooks», PLOS ONE 13, no. 1: e0190807 (2018): 1-24. https://doi.org/10.1371/journal.pone.0190807 (consultado el 14-2-2019)

${ }^{61}$ Salami y Ghajarieh, «Culture and Gender».

62 Al respecto destacamos el completo y exhaustivo trabajo de Hernández-Laina, sin embargo, este se dedica principalmente a enmarcar su influencia en la configuración de identidades políticas, dejando omitidas cuestiones de género. Yovana Hernández-Laina, «Cultura económica y socialización política en los manuales escolares del tardofranquismo y la Transición española, 1960-1985» (Tesis doctoral, Universidad Nacional de Educación a Distancia, 2018).
} 


\section{INVESTIGACIÓN: IDENTIDAD PROFESIONAL Y SOCIALIZACIÓN DE GÉNERO DESDE LA MANUALÍSTICA ESCOLAR EN LA DEMOCRACIA ESPAÑOLA}

\section{Consideraciones previas}

El objetivo principal que se plantea en nuestra investigación es estudiar la identidad profesional femenina vinculada a la socialización económica difundida a través de los manuales escolares de Lengua y Sociales durante el periodo de la Transición española a la democracia y el momento actual, entendido este desde 2006 hasta nuestros días.

Los objetivos específicos del estudio se centran en:

- Detectar cambios y continuidades respecto al rol laboral atribuido a las mujeres en la manualística escolar de la democracia española.

- Aplicar un análisis de género al texto e imágenes y valorar los posibles sesgos de género respecto a la representación de mujeres y hombres en los manuales influyentes en la socialización diferencial.

- Contribuir con nuestras reflexiones a la sensibilización del profesorado de cara al impulso de una buena selección y utilización del material escolar basada en principios coeducativos.

En total se han examinado veinte manuales escolares de quinto curso de la etapa de Educación General Básica —establecida durante la Transición democrática - y la actual Educación Primaria, ${ }^{63}$ tratando de abarcar las editoriales de mayor difusión e implantación en el ámbito estatal, en ambos periodos históricos. Algunas de ellas son grandes grupos editoriales como Anaya y Santillana (véase tabla 2), los cuales se han convertido en referentes en la construcción de modelos de aprendizaje y en el desarrollo de contenidos curriculares. ${ }^{64}$ Los libros de texto seleccionados

\footnotetext{
${ }_{63}$ Se ha tenido acceso a este material mediante diferentes estancias a bibliotecas de provincias españolas, así como al Centro Internacional de la Cultura Escolar (CEINCE), situado en Berlanga de Duero (Soria) y dirigido por Agustín Escolano Benito.

${ }^{64}$ Manuel de Puelles, "La política del libro escolar. Del franquismo a la restauración democrática», en Historia ilustrada del libro escolar en España: de la posguerra a la reforma educativa, ed. Agustín Escolano (Madrid: Fundación Germán Sánchez Ruipérez, 1998), 49-72. En la etapa actual, las
} 
tratan de servir de ejemplo para ilustrar — evitando generalizacionesel papel económico atribuido a la mujer en el currículum escolar de la Transición democrática ${ }^{65}$ —marcado por la Ley General de Educación de 1970- y en el periodo más reciente que consideramos a partir de la Ley Orgánica 2/2006, de 3 de mayo, de Educación —al incorporar medidas explícitas para alcanzar la igualdad efectiva desde el punto de vista de la coeducación en los centros educativos-.

Tabla 2. Manuales escolares analizados (editoriales y año de publicación)

\begin{tabular}{|c|c|c|c|c|}
\hline & \multicolumn{2}{|c|}{ Transición } & \multicolumn{2}{|c|}{ Actualidad } \\
\hline \multirow{7}{*}{ Lengua } & Editorial & Ã̃o & Editorial & Año \\
\hline & Anaya & 1979 & Anaya & 2006 \\
\hline & Miñón & 1977 & Edelvives & 2009 \\
\hline & & & & \\
\hline & Bruño & 1982 & Santillana & 2009 \\
\hline & Everest & 1982 & $\mathrm{SM}$ & 2010 \\
\hline & Santillana & 1982 & Anaya & 2011 \\
\hline \multirow{5}{*}{ Sociales } & Santillana & 1976 & Edelvives & 2009 \\
\hline & Anaya & 1979 & $\mathrm{SM}$ & 2014 \\
\hline & Edelvives & 1979 & Anaya & 2015 \\
\hline & Barcanova & 1982 & Edebé & 2015 \\
\hline & Santillana & 1982 & Santillana & 2015 \\
\hline
\end{tabular}

Fuente: elaboración propia.

editoriales seleccionadas pertenecen, en su mayoría, a la Asociación Nacional de Editores de Libros y Material de Enseñanza -ANELE-. ANELE, «Asociados», https://anele.org/la-asociacion/asociados/ (consultado el 6-7-2019).

${ }_{65}$ A pesar de ser una muestra de tamaño moderado el análisis que se realiza es muy riguroso, lo que permite obtener resultados de interés científico para el ámbito de la manualística escolar y la Historia de la Educación de las mujeres. 
La metodología empleada en este trabajo ha sido cuantitativa, y ello ha condicionado los instrumentos de recogida de datos. Se ha elaborado un fichero electrónico en el que se han volcado más de 155.000 datos pertenecientes a la muestra. La base de datos ad hoc ha sido diseñada mediante el Software de IBM SPSS Statistics Versión 25, utilizando un procedimiento estadístico de tipo descriptivo al permitir trabajar rigurosamente con grandes cantidades de datos y favorecer la obtención de información relevante acerca de múltiples variables ${ }^{66}$ como: etapa estudiada, asignatura, género de los personajes, bloque de texto escolar, bloque de imágenes, editorial, etc. Como unidad de análisis, se ha tomado el personaje humano ${ }^{67}$ tanto para examinar y cuantificar la presencia y ausencia de figuras femeninas, como para determinar su relevancia y representación en el ámbito económico. Cabe mencionar que absolutamente todos los personajes mencionados —en el texto-, e ilustrados —en las imágenes- en cada uno de los manuales han sido examinados en nuestra investigación para obtener una visión completa y globalizada, siendo este nuestro criterio de búsqueda y selección.

Para el análisis del texto escolar se han seguido las orientaciones de López-Navajas, por lo que los personajes pertenecientes a los libros de texto se han clasificado atendiendo a las variables modo - forma en la que aparecen mencionados los personajes según su género- y lugar —ubicación en la que son representados atendiendo a su género- ${ }^{68}$ Encuanto al bloque de imágenes, se ha realizado un análisis pormenorizado aplicado a cada uno de los personajes que aparecen en las ilustraciones determinando su género, el tipo de actividades que desarrolla, la obtención o no de remuneración económica por la misma, el sector económico al que pertenece, etc.

\footnotetext{
${ }^{66}$ Jose Luis Abreu, «Hipótesis, Método y Diseño de Investigación», Dena: International Journal of Good Conscience 7, no. 2 (2012): 187-197; Víctor Álvarez et al., Diseño y evaluación de programas (Madrid: EOS, 2002).

${ }^{67}$ Empleada previamente en otras investigaciones sobre sexismo y manualística escolar, consulte: Garreta y Careaga, Modelos masculinos y femeninos en los textos de EGB; Blanco, El sexismo en los materiales educativos de la E.S.O; López-Navajas, "Las mujeres que nos faltan».
}

${ }^{68}$ López-Navajas, «Las mujeres que nos faltan», 95-98. 


\section{Resultados del estudio}

Análisis del texto escolar

En primer lugar, se realizan unas breves anotaciones respecto a la representación femenina dentro del contenido textual de los manuales escolares de nuestra muestra, ya que permite situar y contextualizar la posición de los personajes femeninos en este recurso didáctico a lo largo de la democracia española para poder profundizar seguidamente en su papel dentro del mundo laboral.

En los veinte manuales escolares examinados se han analizado un total de 2.164 personajes. Si desglosamos los resultados por periodo histórico y área de conocimiento, observamos un incremento del 10,4\% en la presencia de mujeres desde la Transición hasta la actualidad (véase tabla 3), siendo mayor este progreso en el área de Lengua $(11,14 \%)$ que en la de Sociales $(7,45 \%)$. De manera general, existe un desequilibrio patente respecto a la presencia masculina, puesto que, incluso en los libros de hoy en día, ocupan un espectacular y desmesurado protagonismo.

Tabla 3. Porcentajes de presencia personajes en el propio texto

\begin{tabular}{ccccccc} 
& & & Transición & & \multicolumn{3}{c}{ Actualidad } \\
& Lengua & Sociales & Total & Lengua & Sociales & Total \\
Mujeres & 21,78 & 6,30 & 17,65 & 32,92 & 13,55 & 28,05 \\
Hombres & 78,22 & 93,70 & 82,35 & 67,08 & 86,45 & 71,95 \\
\hline
\end{tabular}

Fuente: elaboración propia.

Un modo realmente significativo que tienen los personajes de aparecer en el material es a través de su propia obra. Para un autor o autora, aparecer vinculado a su trabajo y resultados profesionales — producción literaria, obra gráfica, composición musical...- supone un gran reconocimiento a su labor profesional. Del número total de obras analizadas en nuestra muestra (740), tan solo 104 son de autoría femenina. En los manuales actuales examinados la aparición de obras creadas por mujeres ha incrementado única y notablemente en el área de Lengua, donde 
se ha pasado de un $8,36 \%$ en la Transición a un 24,76\%. A diferencia de los manuales de Lengua más recientes, en el periodo de la Transición, destacamos los llamativos ejemplos encontrados en un libro de la editorial Bruño publicado en 1982 en el que se presentan distintas obras literarias. En la mayoría de los casos, las obras de autoría femenina no son acompañadas de una información adicional donde se destaque la trayectoria y actividad profesional de la creadora, algo que sí se halla para casi todos los autores masculinos. ${ }^{69}$ Este ejemplo, es bastante revelador y permite observar cómo, en un mismo manual, el modo de referirse a estos grandes profesionales depende de su género, legitimando la discriminación y desigualdad hacia la mujer en el mundo laboral. Además, nos ha resultado altamente impactante descubrir que, en los manuales del área de Sociales analizados en nuestra investigación, únicamente se menciona una obra de autoría femenina en cada uno de los periodos estudiados. ${ }^{70}$ De este modo, en la asignatura de Sociales de quinto no se observa una evolución, a lo largo de la democracia española, por intentar introducir y destacar a autoras femeninas relevantes en diferentes campos profesionales en la muestra estudiada.

En relación a estas ideas, la posición de mayor trascendencia y visibilidad que puede alcanzar un personaje en el material se obtiene mediante la combinación de las variables modo y lugar: se produce con una reseña del personaje dentro de cuerpo del texto. En esta categoría de intersección, percibimos una mínima evolución de un 5,95\% a favor de la visibilidad de las mujeres entre los períodos históricos estudiados, pasando de un $13,77 \%$ en la Transición a un 19,72\% en la actualidad. De hecho, son muy pocas las féminas a las que se les otorga un epígrafe completo dedicado a su biografía, contribuciones y logros profesionales.

\footnotetext{
${ }^{69}$ Sirvan los siguientes ejemplos que pretenden aclarar la idea transmitida. En el caso de los hombres, vemos que, junto a su nombre y obras, se añade una información destacable acerca del porqué de su estudio: «Lee con cuidada pronunciación el poema que sigue de Manuel Reina (1856-1905), precursor de la poesía modernista con sus libros "Cromos y acuarelas" y "El jardín de los poetas" " (Carratala y Carratala, 1982: 84). En cuanto a las féminas, solo existen algunos adjetivos que califican la poesía que se va a estudiar, pero no se realza la aportación de las autoras a la literatura. Ejemplos: «Aprende de memoria y recita este breve poema de la poetisa gallega Rosalía de Castro» (Carratala y Carratala, 1982: 85); «La poesía no necesita complicaciones y dificultades. Lo comprobarás leyendo este humanísimo poema de Gloria Fuertes» (Carratala y Carratala, 1982: 56). Fernando Carratala y Domingo Carratala, Arrecife Lengua Castellana (Madrid: Bruño, 1982).

${ }^{70}$ Estas autoras tan excepcionales y con inusual cabida en los manuales de Sociales son Santa Teresa de Jesús (Transición) e Isabel Belmonte López (Actual).
} 
Algunas de las "privilegiadas» son Isabel I de Castilla, Santa Teresa de Jesús, Teresa de Calcuta, Carmen Martín Gaite, Marie Sklodowska-Curie o Simone Veil. Por el contrario, no existe ninguna mujer reseñada en el mundo del deporte, en el ámbito musical y artístico — por solo citar algunos ejemplos podrían incluirse a profesionales tan sobresalientes en nuestra historia como la escultora Properzia de Rossi; las pintoras Maruja Mallo, Artemisia Gentileschi y Frida Kahlo; la compositora Francesca Caccini; las tenistas Charlotte Cooper, y Lilí Álvarez, o la gimnasta Nadia Comăneci, entre muchas otras-. Nótese, en consecuencia, la invisibilidad femenina y las ideas que niños y niñas pueden interiorizar acerca de quiénes son los hacedores de la historia, del conocimiento, del legado cultural y, en definitiva, de quienes contribuyen al avance de la Humanidad.

\section{Análisis de las imágenes}

En este apartado se han examinado la totalidad de personajes representados en las imágenes de los libros de texto. Las ilustraciones de los manuales poseen una carga fundamental en la transmisión de roles profesionales femeninos y masculinos y cuentan con una importante función didáctica para ayudar a la comprensión de los contenidos que en ellos se presentan. ${ }^{71}$ En nuestro estudio, nos centramos en una muestra de manuales dirigidos al alumnado de la etapa de Educación Primaria, en la cual las imágenes tienen un gran valor y significado, al ser el componente del manual que más llama la atención a los niños y niñas. ${ }^{72}$

En total se analizaron 5.555 personajes en las imágenes de los veinte manuales escolares. En el tema que nos ocupa, nos interesa saber cuántos de estos personajes obtienen una remuneración económica por la labor que desempeñan en el material, es decir, aquellos que consideraríamos como población activa. De los 2.000 personajes que reciben un salario por su actividad económica 259 son mujeres. Si bien es cierto que la representación de mujeres en el mundo laboral ha aumentado respecto a la Transición, estas siguen representando una indudable

\footnotetext{
71 Blanco, «Análisis de materiales curriculares».

72 Verónica Cobano-Delgado y Teresa Terrón, «El papel de la mujer en las ilustraciones de los libros de texto de educación primaria», Foro de Educación: Pensamiento 10 (2008): 385-400.
} 
minoría respecto a la proporción masculina en la actualidad de más de un $80 \%$ (véase gráfico 2). Por ello, afirmamos la existencia de una peligrosa discordancia entre lo mostrado en el manual y la realidad sociológica, ya que hoy en día la tasa de actividad femenina es mucho más igualitaria, llegando a alcanzar el $53 \%$ en $2018 .{ }^{73}$

\section{Gráfico 2. Porcentajes de los personajes que obtienen remuneración económica en los manuales escolares analizados}

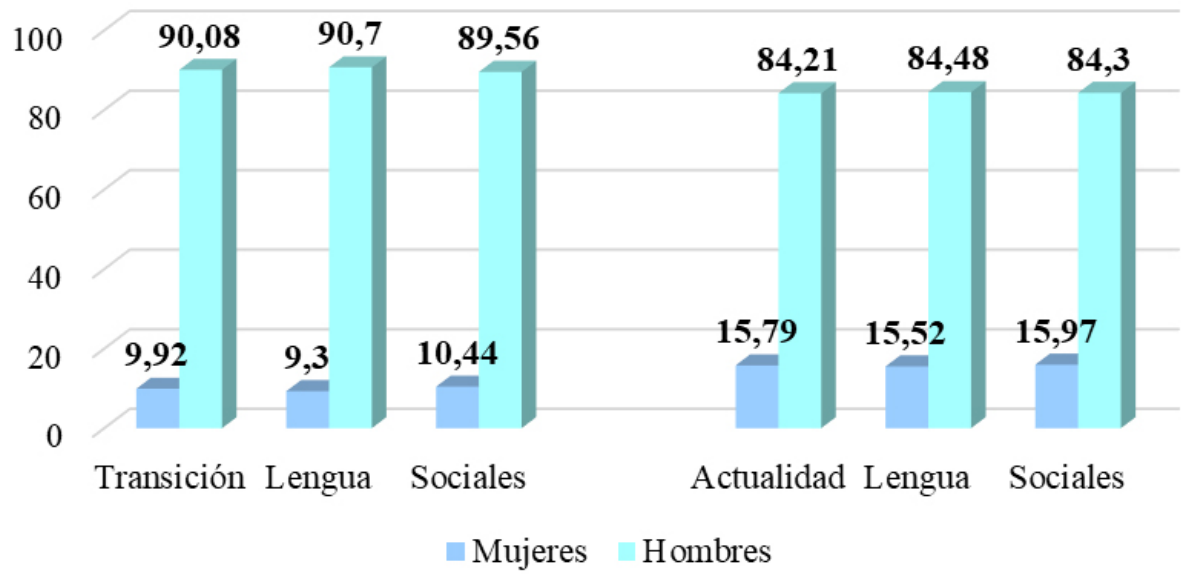

Fuente: elaboración propia.

Otro aspecto en el que consideramos fundamental profundizar es la variedad de trabajos realizados por los personajes femeninos y masculinos. Resulta revelador encontrar más de 300 profesiones diferentes desempeñadas por varones frente a poco más de 50 por parte de las mujeres. Este punto es muy relevante de cara a la construcción de la identidad profesional del alumnado. Los chicos gozan de ejemplos y referentes en prácticamente todo el mercado laboral, de forma que se pueden proyectar y visualizar en cualquier tipo de trabajo; en el caso de las chicas, ocurre lo contrario. En las imágenes analizadas se promueven modelos muy estandarizados y repetitivos (profesoras, enfermeras, pediatras...), en otras palabras, campos vinculados esencialmente a la enseñanza y los cuidados que no reflejan todo el abanico profesional a las que ellas podrían acceder en el futuro. Como apuntábamos anteriormente, los

\footnotetext{
${ }^{73}$ INE, «Encuesta de población activa».
} 
libros de texto estudiados van "por detrás» del retrato económico que encontramos en la sociedad española. No solo nos referimos a la falta de compromiso por fomentar un repertorio laboral más amplio para las mujeres, sino que además presentan una regresión respecto a la realidad sociológica en términos de población y empleo, por lo que ni siquiera reflejan la realidad.

A fin de completar estas reflexiones realizamos una lectura rigurosa del recurso didáctico prestando especial atención a las referencias respecto a la incorporación de la mujer al mundo del trabajo. Las escasas alusiones a este tema, que hemos encontrado en nuestra muestra, se limitan a su repercusión en la natalidad, incluso en los manuales más recientes, por ejemplo: «La natalidad en España fue muy alta hasta la década de 1970 [...]. Algunas de las razones de ese descenso son la incorporación de las mujeres al mundo laboral y el retraso de la edad a la que las mujeres tienen hijos». ${ }^{74}$ Así, se proporciona una visión que puede ser considerada como "negativa», en la que su decisión de formar parte de la población activa las «responsabiliza» de una de las tasas de nacimiento más bajas de Europa. Se proporciona una información parcial e incompleta en la que se omiten cuestiones enunciadas por autoras como María del Rosario Marín como las dificultades de conciliación familiar-laboral, la renta del hogar, los costes de oportunidad laboral y la falta de políticas o prestaciones familiares..$^{75}$ Tampoco se comenta cómo afectó positivamente la entrada del empleo femenino al bienestar social y económico de las familias, incrementando sus ingresos medios y su calidad de vida, ni se realizan alusiones al ahorro económico en el presupuesto familiar que supone el trabajo doméstico y los cuidados, actividades desempeñadas en mayor medida por mujeres ${ }^{76}$ —nada extraño si tenemos en cuenta la devaluación social que persiste actualmente entorno a estas labores-. Por el contrario, consideramos que desde la escuela y los libros de texto se debe reconocer la importancia de la

\footnotetext{
${ }^{74}$ Mar García et al., Ciencias Sociales 5 primaria (Madrid: Santillana, 2015): 86.

${ }_{75}$ María del R. Marín, «Tasa de actividad femenina y fecundidad. ¿Ser madre o ser activa?», Boletín Económico de ICE 2723 (2002): 21-28.

${ }^{76}$ Si profundizamos en el número medio de horas dedicado a estas obligaciones se registraron 4h 7' en el caso de las mujeres y 1h 54' para los hombres. INE, «Encuesta de empleo del tiempo». https:// www.ine.es/dyngs/INEbase/es/operacion.htm?c=Estadistica_C\&cid=1254736176815\&menu=resultados\&idp=1254735976608 (consultado el 22-12-2019).
} 
economía de cuidados para el bienestar social, al ser pieza clave en el desarrollo de la autonomía personal.

Por otra parte, las actividades económicas remuneradas fueron clasificadas en los diferentes sectores profesionales. Se ha encontrado que en la Transición los datos de los manuales de Sociales examinados se ajustan mejor a la realidad sociológica del momento - sector primario $(29,09 \%)$, sector secundario $(32,73 \%)$ y sector terciario $(38,18 \%)$ - que los actuales. En dicho periodo se observa una alta proporción de mujeres en el sector secundario, pero circunscritos a una clara segregación horizontal: la mujer suele encontrarse representada en la industria textil —considerada tradicionalmente como extensión de las labores domésticas y empleos circunscritos a las destrezas femeninas para las habilidades manuales aprendidas en el seno del hogar-, ${ }^{77}$ los varones en dicho sector aparecen vinculados a la industria siderúrgica o a la construcción — para las cuales se valoran habilidades como la fuerza física...-. Así, se perpetúan ideologías sexistas y una división sexual del trabajo acorde a estereotipos tradicionales.

Coincidiendo con las características del sistema económico español, la mayor parte de las féminas desempeñan profesiones encuadradas dentro del sector terciario - $62,99 \%$ en los manuales analizados de la Transición y 85,62\% en los más actuales-; por lo que creemos que es esencial un examen más riguroso de este ámbito. Entre los servicios que han permanecido prácticamente invariables con muy poca inclusión de mujeres, a lo largo de los años de democracia abarcados en nuestra muestra, encontramos los vinculados a la protección y a la seguridad - cuerpo de policías, cuerpo contra incendios, salvamento...-. En los manuales de la Transición examinados no hallamos ninguna figura femenina representada en este tipo de empleos y en el periodo más reciente solo hemos contabilizado tres mujeres (imágenes 1,2 y 3 ).

\footnotetext{
77 Luz G. Arando, «Industria textil y saberes femeninos», Historia Crítica 9 (1994): 1-6.
} 

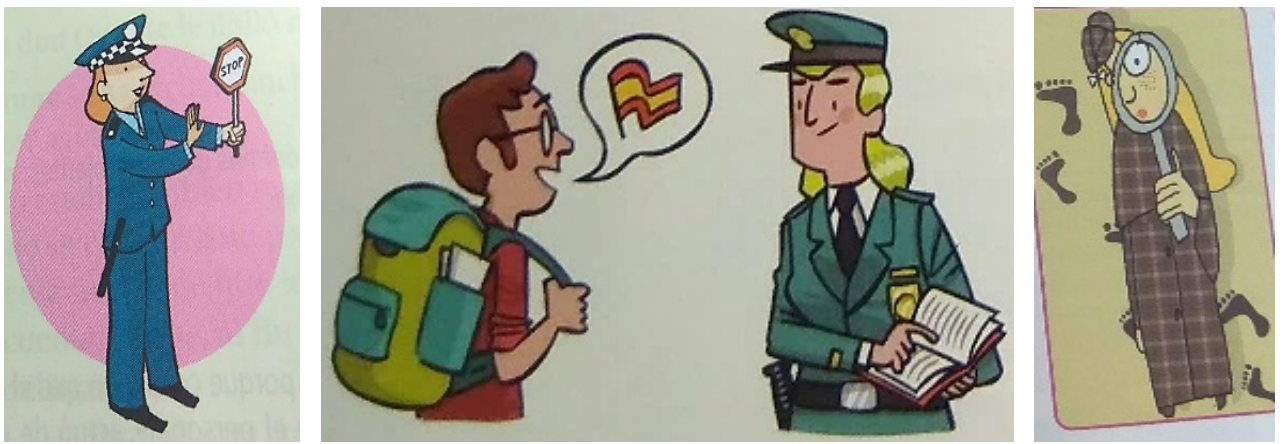

Imágenes 1, 2 y 3. Representación de una mujer policía ${ }^{78}$; Representación de una mujer guardia civil $^{79}$ y Representación de una mujer detective. ${ }^{80}$

En particular, destacamos una ilustración en la que se presenta a una mujer policía en un manual de Lengua actual de la editorial Edelvives (imagen 1). Junto a ella, se introduce la siguiente actividad: ¿ ¿Crees que los hombres y las mujeres tienen las mismas capacidades? ¿Consideras que hay trabajos o tareas que son solo para hombres y otras solo para mujeres? ¿Por qué?». ${ }^{81}$ Debido a que uno de nuestros propósitos es establecer recomendaciones y sensibilizar al profesorado de cara a la buena elección y el uso del material, nos gustaría señalar que estos ejercicios pueden ser muy enriquecedores si se trabajan de forma adecuada, pero también peligrosos si el profesorado no dispone de una formación básica en materia de género. Es fundamental el enfoque desde el que se planteen estas cuestiones relacionadas con el mundo laboral en un aula de primaria, ya que puede derivar en que se genere un debate a favor o contrario a principios coeducativos, es decir, podrían incluso salir a la luz prejuicios del alumnado o de los propios docentes que legitimaran una cultura laboral jerárquica y sesgada. En cambio, un buen modo de abordar esta temática podría ser tratando de desvelar el origen que ha llevado tradicionalmente a considerar dichos trabajos como «femeninos» o «masculinos» desmontando los estereotipos de género.

\footnotetext{
78 Claudia Araya y Manuel García, Lengua 5 (Zaragoza: Edelvives, 2009), 152.

${ }^{79}$ Ezequiel Parra et al., Ciencias Sociales 5. Andalucía (Madrid: SM, 2014), 76

${ }^{80}$ Araya y García, Lengua 5, 152

${ }^{81}$ Araya y García, Lengua 5.
} 
También percibimos una escasa participación femenina en empleos relacionados con los ámbitos de transporte de personas y mercancías, justicia, deportivo y mantenimiento, ${ }^{82}$ a excepción de los servicios de limpieza donde constituyen el 70\% del total de personajes analizados en la muestra, tarea que bajo la mirada androcéntrica supone una prolongación de las del cuidado del hogar propio. Además, en nuestra sociedad globalizada, cada vez cobra más importancia el sector cuaternario que incluye los servicios dirigidos al desarrollo y la investigación de nuevas tecnologías. Las personas empleadas en estos puestos de trabajo suelen tener una alta capacitación profesional y sueldos elevados. Estas consideraciones son relevantes dada la escasez de mujeres representadas en los manuales escolares de la muestra. Se las excluye de uno de los sectores más punteros y de mayor reconocimiento social en la actualidad. A diferencia del periodo de la Transición, los diez libros más recientes estudiados incluyen solamente a cinco mujeres en este ámbito.

Por último, en el material curricular analizado encontramos una patente segregación vertical en las diferentes categorías y servicios profesionales. Los personajes masculinos ocupan puestos o cargos de mayor responsabilidad: presidentes, médicos, jefes, empresarios, directores, etc.; en cambio, a ellas se les asignan puestos de peor reconocimiento y remuneración que supone la manifestación evidente del llamado techo de cristal (imágenes 4 y 5) y que constituye en la actualidad uno de los grandes impedimentos a nivel mundial para la consecución de la igualdad en el mercado laboral.

\footnotetext{
${ }^{82}$ En los manuales estudiados encontramos una escasa proporción de personajes femeninos en los citados empleos, que alcanzan como máximo la abrumadora e insignificante cifra de dos personajes en cada servicio. Por ende, su variedad profesional es mucho menor a la masculina, por ejemplo: en el mundo del deporte solo encontramos a una mujer tenista en la Transición y a equilibrista en el periodo actual. En cambio, entre los varones deportistas sus perfiles son muy heterogéneos (árbitros, esquiadores, gimnastas, alpinistas, jugadores de baloncesto, futbolistas, nadadores, ciclistas, tenistas, jinetes, boxeadores...).
} 


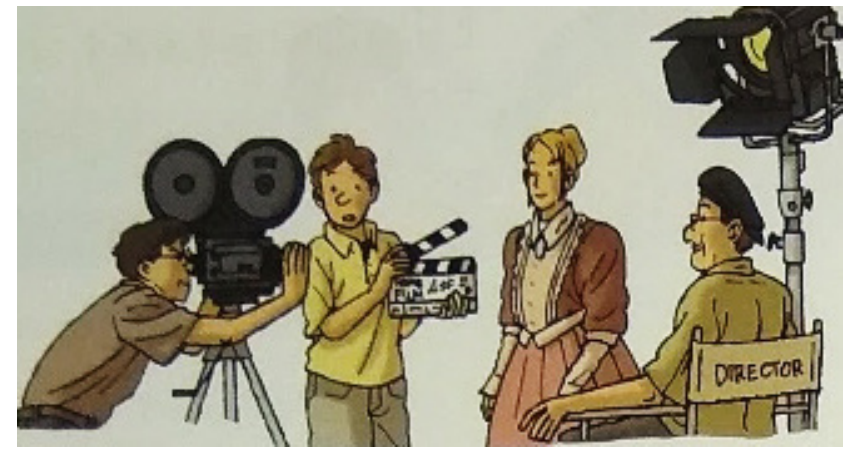

Imagen 4. Representación de la segregación horizontal y vertical en el mundo laboral ${ }^{83}$

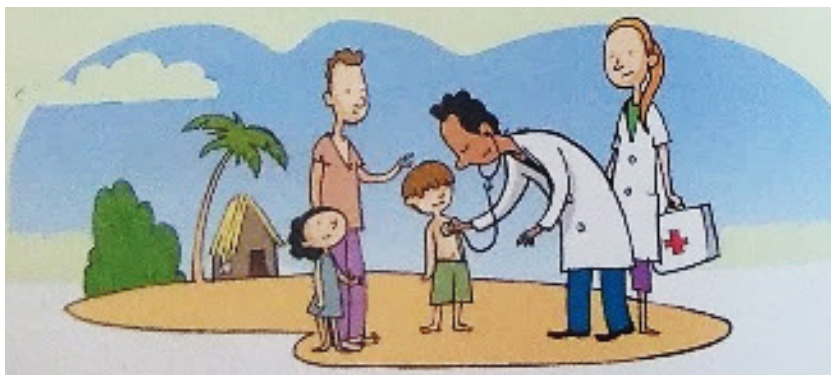

Imagen 5. Posición secundaria de la figura de la mujer en el ámbito sanitario. ${ }^{84}$

\section{CONCLUSIONES}

En la configuración de la identidad personal convergen y tienen fundamental cabida los discursos cultural e históricamente construidos en torno a cuestiones de género que son divulgados desde los distintos agentes de socialización. Entre ellos, destacamos fundamentalmente la escuela. El currículum escolar actúa como reflejo del imaginario social y se materializa a través de los libros de texto.

La presente investigación se ha centrado en el análisis de las referencias relativas a la identidad profesional vinculada a la socialización

\footnotetext{
${ }^{83}$ Begoña Oro et al., Lengua 5 Primaria (Madrid: SM, 2010), 210.

${ }^{84}$ Araya y García, Lengua 5,116
} 
económica y las discriminaciones de género difundidas a través de una selección de veinte manuales escolares de Lengua y Sociales de quinto de primaria pertenecientes a la época de la Transición española y el momento actual. Se incluye un exhaustivo análisis de género en el que se ha examinado cuantitativamente el contenido de cada manual (texto e imágenes), a partir del cual se ha podido reflexionar sobre el ajuste o desajuste entre la realidad económica experimentada por las mujeres durante la evolución de la España democrática, con lo expuesto en el material, considerando su posible influencia en la construcción y transmisión de una cultura sociolaboral sesgada.

Los resultados obtenidos en nuestro estudio revelan una falta de reconocimiento a la labor profesional de las mujeres en la historia. Las obras de autoría femenina constituyen un legado que forma parte de nuestra cultura y deberían estar presentes de manera equitativa. Si bien es cierto que se ha producido un notable incremento en la inclusión de obras creadas por mujeres en los manuales más recientes de Lengua analizados — como las de Carmen Laforet, Carmen Martin Gaite, Cecilia Böhl de Faber, Rosalía de Castro, Emilia Pardo Bazán, Santa Teresa de Jesús...-. Sin embargo, su proporción no llega al 25\% respecto a la totalidad de obras presentes en el material, es decir, integrando las masculinas. Un patrimonio que presenta un fuerte androcentrismo y que se intensifica en el caso de los libros de texto de Sociales estudiados, en los que solo se encuentra una obra femenina en cada periodo histórico. De las evidencias anteriores, detectamos avances y continuidades respecto al papel de la mujer en el mercado profesional. En los libros investigados, persiste una falta de reconocimiento a mujeres creadoras, artistas e inventoras, que podría generar una falsa e incompleta interpretación de la realidad por parte del alumnado, en la que se imagine a la figura del varón como único capaz de crear producciones relevantes para la humanidad.

Respecto a la actividad económica desarrollada por las mujeres, en las imágenes de los manuales estudiados, escasean los personajes femeninos que obtienen una remuneración salarial por las actividades que desempeñan. En los dos periodos históricos estudiados y dentro de la muestra, representan de media el 13\% del total de personajes que obtienen un salario, resultado que no se corresponde en absoluto con la situación económica de inicios de la democracia, ni mucho menos con nuestros días. 
Constatamos que esta disparidad es aún mayor cuando en nuestro estudio revelamos la ausencia de diversidad profesional femenina. Por un lado, unos cincuenta empleos diferentes se presentan como «adecuados» para las niñas y se constituyen como referentes en los que pueden encajar, presentando una clara invisibilidad profesional en ámbitos como la ciencia, la protección y seguridad, los deportes, etc. Por otro, hay más de trescientos oficios ocupados por personajes masculinos $\mathrm{y}$, además, estos se sitúan en los cargos de mayor prestigio y responsabilidad, para los cuales se les atribuyen las características de un «buen líder» — autoridad, inteligencia, racionalidad...-. Así, se les percibe en el material como más afines para ejercer dichos puestos. Por tanto, el discurso que se difunde refuerza la hegemonía patriarcal y las estructuras de poder existentes en la sociedad para mantener el estatus quo.

En base a nuestros resultados, podemos afirmar que los manuales escolares examinados promueven roles y estereotipos sociales diferenciados por género que no son ajenos al mercado laboral, pudiendo influir en las percepciones de las personas acerca de sus capacidades desde edades realmente tempranas. A través de este material se difunden una fuerte socialización diferencial en el mercado de trabajo que traspasa el paso del tiempo y los avances transcurridos durante la democracia española —según los manuales empleados en el análisis-. Estos sesgos son altamente peligrosos pues desde primaria el alumnado asocia actividades y profesiones que requieren de un elevado nivel intelectual y brillantez únicamente a los hombres. ${ }^{85}$ En este sentido, los roles reflejados en estos manuales contienen una evidente segregación vertical y horizontal del trabajo en función del sistema sexo-género que podría llegar a restringir la futura elección de una carrera profesional en las chicas, ocasionando una pérdida de talento y capital humano. Atendiendo a estas consideraciones, declaramos la necesidad de continuar profundizando en el análisis de manuales escolares desde la perspectiva de género, así como sensibilizar al profesorado sobre la buena selección y utilización de este material desde la coeducación —los indicadores y sugerencias prácticas presentadas a lo largo del artículo pueden servirles para entrenar la mirada de género, por lo que resultan de gran utilidad y aplicabilidad-. Afirmamos que este recurso educativo debería promover

${ }^{85}$ Lin Bian, Sarah-Jane Leslie y Andrei Cimpian, "Gender stereotypes about intellectual ability emerge early and influence children's interests», Science 355 (2017): 389-391. 
una orientación laboral lo más diversa posible basada en la igualdad de oportunidades entre los géneros, creando genealogía y referentes que sirvan de inspiración a las niñas, especialmente en aquellos empleos tradicionalmente considerados como «ajenos a su género». De este modo, las chicas contarían con una mayor libertad de elección y se lucharía a favor de la eliminación de las barreras que las mujeres han ido interiorizando en la sociedad y que limitan su autoestima, intereses, confianza, autovaloración y expectativas en la construcción de su identidad personal y profesional. La renovación de los libros de texto es uno de los pasos para alcanzar un modelo económico más justo e igualitario en el que se valoren todas las actividades humanas, incluida le economía de cuidados, y en el que el género no sea una variable que condicione el empleo desempeñado, buscando construir desde los pilares de nuestra infancia una cultura socio-laboral no sesgada.

\section{Nota sobre las autoras}

Virginia Guichot Reina es Doctora en Pedagogía ${ }^{86}$ y en Filosofía ${ }^{87}$ por la Universidad de Sevilla. Actualmente es Profesora Titular del Departamento de Teoría e Historia de la Educación y Pedagogía Social de dicha Universidad. Su principal línea de investigación gira en torno al tema «Ciudadanía democrática y educación», contando con numerosas publicaciones al respecto. Ha formado parte de varios proyectos de $\mathrm{I}+\mathrm{D}+\mathrm{i}$, siendo el último el titulado Economía, patriotismo y ciudadanía: La dimensión económica de la socialización política en los manuales escolares españoles desde el Tardofranquismo hasta la Transición, coordinado por Manuel Ferraz Lorenzo. Es la directora de un ciclo de conferencias sobre «Educación para la ciudadanía», de carácter interdisciplinar, que se viene celebrando en la Universidad de Sevilla durante los últimos doce años.

Ana María de la Torre Sierra es graduada en Educación Infantil (2017) y Máster en Estudios de Género y Desarrollo Profesional (2018) por la

\footnotetext{
${ }^{86}$ Virginia Guichot-Reina, Democracia, ciudadanía y educación una mirada crítica sobre la obra pedagógica de John Dewey (Madrid: Biblioteca Nueva, 2003).

${ }^{87}$ Virginia Guichot-Reina, Reconstruir la ciudadanía (Madrid: Dykinson, 2013).
} 
Universidad de Sevilla (US). En esta institución actualmente cursa los estudios de Doctorado en Educación para ello, le han concedido un contrato predoctoral de formación de profesorado universitario (FPU) por el Ministerio de Ciencia, Innovación y Universidades, en el Departamento de Teoría e Historia de la Educación y Pedagogía Social de la US. Su línea de investigación se centra en observar el papel social, político, económico y cultural que se atribuye a la mujer en los manuales escolares y su influencia en el proceso de socialización y construcción de la identidad personal y profesional femenina. Recientemente ha sido galardonada con el premio a la mejor investigación novel en materia de género por el Ayuntamiento de Sevilla en la «I Edición de los premios de la mujer en investigación y creación literaria de la ciudad de Sevilla».

\section{REFERENCIAS}

Abreu, Jose Luis. «Hipótesis, Método y Diseño de Investigación». Dena: International Journal of Good Conscience 7, no. 2 (2012): 187-197.

Addabbo, Tindara, Marie-Pierre Arrizabalaga, Cristina Borderías y Alastir Owens. Gender Inequalities, Households and the Production of Well-Being in Modern Europe. Londres: Routledge, 2010.

Alba, Alfonso. La riqueza de las familias: Mujer y mercado de trabajo en la España democrática. Barcelona: Ariel, 2000.

Álvarez, Víctor, Eduardo García, Javier Gil, Pilar Martínez, Javier Rodríguez y Soledad Romero. Diseño y evaluación de programas. Madrid: EOS, 2002.

Arando, Luz G. «Industria textil y saberes femeninos». Historia Crítica 9 (1994): 1-6. Araya, Claudia y Manuel García. Lengua 5. Zaragoza: Edelvives, 2009.

Balaguer, María Luisa. Mujer y Constitución: La construcción jurídica del género. Madrid: Ediciones Cátedra, 2005.

Barberá, Esther. «Perspectiva cognitivo-social: estereotipos y esquemas de género». En Psicología y Género, editado por Esther Barberá, Isabel Martínez y Amparo Bonilla, 55-80. Madrid: Pearson, Prentice Hall, 2004.

Bautista, Esperanza. «Mujer y democracia en España: evolución jurídica y realidad social». Documentación Social 105 (1996): 49-73.

Bel, Juan Carlos. «Imagen y libros de texto de Historia en Educación Primaria: estudio comparativo a partir de un análisis cualitativo». Revista de Educación 377 (2017): 82-112.

Bian, Lin, Sarah-Jane Leslie y Andrei Cimpian. «Evidence of bias against girls and women in contexts that emphasize intellectual ability». American Psychologist 73, no. 9 (2018): 1139-1153. 
Bian, Lin, Sarah-Jane Leslie y Andrei Cimpian. «Gender stereotypes about intellectual ability emerge early and influence children's interests». Science 355 (2017): 389-391.

Blanco, Nieves. «Análisis de materiales curriculares». En Mujer y educación una perspectiva de género, editado por Ana Vega, 105-115. Málaga: Ediciones Aljibe, 2007.

Blanco, Nieves. El sexismo en los materiales educativos de la E.SO. Sevilla: Instituto Andaluz de la Mujer, 2000.

Borderías, Cristina y Lina Gálvez-Muñoz. «Cambios y continuidades en las desigualdades de género. Notas para una agenda de investigación». Areas: Revista Internacional de Ciencias Sociales 33 (2014): 7-15.

Bruner, Jerome. "Meaning and Self in Cultural Perspective». En The social self, editado por David Bakhurst y Christine Sypnowich, 18-30. Londres: Sage, 1996.

Bruner, Jerome. Acts of Meaning. Cambridge: Harvard University Press, 1990.

Burr, Vivien. An introduction to social constructionism. London: Routledge, 1995.

Cabrera, Luis Alberto. Mujer, trabajo y sociedad (1839-1983). Madrid: Fundación Francisco Largo Caballero, 2005.

Caro, Coral. «Un amor a tu medida. Estereotipos y violencia en las relaciones amorosas». Revista de Estudios de Juventud 83 (2008): 213-228.

Carrasco, Cristina. "El cuidado como eje vertebrador de una nueva economía». Cuadernos de Relaciones Laborales 31, no. 1 (2013): 39-56.

Carratala, Fernando y Domingo Carratala. Arrecife Lengua Castellana. Madrid: Bruño, 1982.

Choppin, Alain. «L'histoire des manuels scolaires: une approche globale». Histoire de l'Education 9 (1980): 1-25.

Cifre, Eva, María Vera, Israel Sánchez-Cardona y Nele de Cuyper. «Sex, Gender Identity, and Perceived Employability among Spanish Employed and Unemployed Youngsters». Frontiers in Psychology 9, no. 2467 (2018): 1-12.

Cobano-Delgado, Verónica y Teresa Terrón. «El papel de la mujer en las ilustraciones de los libros de texto de educación primaria». Foro de Educación: Pensamiento 10 (2008): 385-400.

Colás, Pilar y Patricia Villaciervos. «La interiorización de los estereotipos de género en jóvenes y adolescentes». Revista de Investigación Educativa 25, no. 1 (2007): 35-58.

Collin, Audrey y Richard A. Young. "The future of career». En The future of career, editado por Audrey Collin y Richard A. Young, 276-300. Cambridge: Cambridge University Press, 2002.

De Puelles, Manuel. «La política del libro escolar. Del franquismo a la restauración democrática». En Historia ilustrada del libro escolar en España: de la 
posguerra a la reforma educativa, editado por Agustín Escolano, 49-72. Madrid: Fundación Germán Sánchez Ruipérez, 1998.

Fernández, M. Pilar y Presentación A. Caballero. «El libro de texto como objeto de estudio y recurso didáctico para el aprendizaje: fortalezas y debilidades». Revista Electrónica Interuniversitaria de Formación del Profesorado 20, no. 1 (2017): 201-217.

Folguera, Pilar. «Integrando el género en la agenda política. Feminismo, Transición y democracia». En 100 Años en femenino. Una historia de mujeres en España, editado por Isabel Tejeda y María O. Rubio, 98-121. Madrid: Asociación Cultural Española Conde Duque, 2012.

Fundación Foessa. Estudios sociológicos sobre la situación social de España, 1975. Madrid: Euroamérica S.A., 1976.

Gahete, Soraya. «Las luchas feministas. Las principales campañas del movimiento feminista español (1976-1981)». Investigaciones feministas 8, no. 2 (2017): 583-601.

García, Mar, Álvaro Bellón, Aurora Moral, Antonia Perales, Ana I. Pérez, Pilar Tamos, Raquel Rubalcaba y Esther Echevarría. Ciencias Sociales 5 primaria. Madrid: Santillana, 2015.

Garreta, Nuria y Pilar Careaga. Modelos masculinos y femeninos en los textos de EGB. Madrid: Instituto de la Mujer, 1987.

Gergen, Kenneth J. Realities and relationships: Soundings in social construction. Cambridge: Harvard University Press, 1994.

Gil, Juana M. «Repensando la constitución: Una mirada al deber de trabajar y al derecho al trabajo». Revista de Derecho Político 104 (2019): 59-85.

Gouvias, Dionysios y Christos Alexopoulos. "Sexist stereotypes in the language textbooks of the Greek primary school: a multidimensional approach». Gender and Education 30, no. 5 (2018): 642-662.

Graziano, William G., Meara M. Habashi y Demetra Evangelou. «Orientations and motivations: Are you a "people person", a "thing person", ¿or both?». Motivation and Emotion 36 (2012): 465-477.

Guichot-Reina, Virginia. Democracia, ciudadanía y educación una mirada crítica sobre la obra pedagógica de John Dewey. Madrid: Biblioteca Nueva, 2003.

Guichot-Reina, Virginia. Reconstruir la ciudadanía. Madrid: Dykinson, 2013.

Hernández-Laina, Yovana. «Cultura económica y socialización política en los manuales escolares del tardofranquismo y la Transición española, 19601985» PhD diss., Universidad Nacional de Educación a Distancia, 2018.

Herrero, Yayo. "Miradas ecofeministas para transitar a un mundo justo y sostenible». Revista de economía crítica 16 (2013): 278-307.

Hymowitz, Carol y Timothy D. Schellhardt. «The glass ceiling: Why women can't seem to break the invisible barrier that blocks them from top jobs». The Wall Street Journal 24, no. 1 (1986): 1573-92. 
Islam, Kazi Md. Mukitul y M. Niaz Asadullah. «Gender stereotypes and education: A comparative content analysis of Malaysian, Indonesian, Pakistani and Bangladeshi school textbooks». PLOS ONE 13, no. 1: e0190807 (2018): 1-24.

Lagarde, Marcela. Género y feminismo: Desarrollo humano y democracia. Madrid: Horas y Horas, 1996.

Lerchenmueller, Marc, Olav Sorenson y Anupam B. Jena, "Gender differences in how scientists present the importance of their research: Observational study». The BMJ 367, no. 16573 (2019): 1-8.

López-Navajas, Ana. "Las mujeres que nos faltan: análisis de la ausencia de las mujeres en los manuales escolares». PhD diss., Universitat de València, 2015.

Maalouf, Amin. Identidades asesinas. Madrid: Alianza editorial, 1999.

Magnusson, Charlotta y Magnus Nermo. «From childhood to young adulthood: the importance of self-esteem during childhood for occupational achievements among young men and women». Journal of Youth Studies 21, no. 10 (2018): 1392-1410.

Marañón, Iría. Educar en el feminismo. Barcelona: Plataforma editorial, 2008.

Marín, María del R. «Tasa de actividad femenina y fecundidad. ¿Ser madre o ser activa?». Boletín Económico de ICE 2723 (2002): 21-28.

Moreno-Seco, Mónica. «Sexo, Marx y Nova Cançó. Género, política y vida privada en la juventud comunista de los años setenta». Historia Contemporánea 54 (2017): 47-84.

Oro, Begoña, Carmen Gil, Meritxell Martí, Mª Rosario González, Olalla Hernández, Samuel Alonso y Amparo Cantalejo. Lengua 5 Primaria. Madrid: SM, 2010.

Parcerisa, Arthur. Materiales curriculares: cómo elaborarlos, seleccionarlos y usarlos. Barcelona: Grao, 1996.

Parham, Fatemeh. "Gender Representation in Children's EFL Textbooks». Theory and Practice in Language Studies 3, no. 9 (2013): 1674-1678.

Parra, Ezequiel, Sara Martín, Antonio J. Hidalgo, Alberto Navarro y Sergio López. Ciencias Sociales 5. Andalucía.Madrid: SM, 2014.

Pienta, Racgek S. y Ann M. Smith, «Women on the margins: The politics of gender in the language and content of science textbooks». En The new politics of the textbook: Problematizing the portrayal of marginalized groups in textbooks, editado por Heather Hickman y Brad Porfilio, 49-68. Rotterdam: Sense Publishers, 2012.

Porto, Ana María. «La mujer en el siglo XXI y el oficio del matrimonio». En Cuestiones actuales sobre el trabajo de la mujer y su protección social, editado por Asunción López-Arranz, Cristina Faraldo y María del Pilar Millor, 13-36. Valencia: Tirant lo Blanch, 2010. 
Ramaci, Tiziana, Monica Pellerone, Caterina Ledda, Giovambattista Presti, Valeria Squatrito y Venerado Rapisarda. «Gender stereotypes in occupational choice: a cross-sectional study on a group of Italian adolescents». Psychology Research and Behavior Management 10 (2017): 109-117.

Ricoeur, Paul. Sí mismo como otro. Madrid: Siglo XXI, 1996.

Salami, Ali y Amir Ghajarieh. "Culture and Gender Representation in Iranian School Textbooks». Sexuality \& Culture 20 (2016): 69-84.

Santamaría, Andrés y Miguel Ángel Martínez. «La construcción de significados en el marco de un Psicología Cultural: el pensamiento narrativo». En Vygotski en la psicología contemporánea, editado por Mercedes Cubero y Juan Daniel Ramírez, 167-193. Buenos Aires: Miño y Dávila, 2015.

Subirats, Marina. «De la escuela mixta a la coeducación. La educación de las niñas: el aprendizaje de la subordinación». En Mujer y educación una perspectiva de género, editado por Ana Vega, 137-147. Málaga: Ediciones Aljibe, 2007.

Torns, Teresa. «Conciliación de la vida laboral y familiar o corresponsabilidad: ¿El mismo discurso?». RIDEG: revista interdisciplinar de estudios de género 1 (2011): 5-13.

Torns, Teresa. «El trabajo y el cuidado. Cuestiones teórico-metodológicas desde la perspectiva de género». Empiria: Revista de metodología de ciencias sociales 15 (2008): 53-73.

Urruzola, María José. "La educación de las relaciones afectivas y sexuales». Aula de innovación educativa 91 (2000): 30-31.

Usabiaga, Carlos. La segregación laboral de la mujer andaluza: Indicadores, consecuencias y medidas hacia la igualdad de género. Sevilla: Fundación Pública Andaluza Centro de Estudios Andaluces, 2014.

Vázquez, Isabel M. y Ángeles Blanco-Blanco. «Factores sociocognitivos asociados a la elección de estudios científico-matemáticos. Un análisis diferencial por sexo y curso en la Educación Secundaria». Revista de Investigación Educativa 37, no. 1 (2019): 269-286. 